\title{
ПРОТИВОДЕЙСТВИЕ ЭКСТРЕМИЗМУ (ТЕРРОРИЗМУ) В РОССИИ СРЕДСТВАМИ ПРОКУРОРСКОГО НАДЗОРА
}

\section{COUNTERING EXTREMISM (TERRORISM) IN RUSSIA BY MEANS OF PROSECUTOR'S SUPERVISION}

T. Zaiko

\section{G. Pantyukhina}

Summary: The article describes various forms of extremism that provoke instability in society, contribute to the weakening of the Russian state, generate separatist sentiments in certain regions of the Russian Federation and create a favorable opportunity for extremists to realize their goals and objectives. This circumstance leads to a violation of human and civil rights and freedoms, undermines public security and state integrity. Creates a real threat to the foundations of the constitutional order. Because the essence of terrorism is violence for the purpose of intimidation. Terrorism is an extreme manifestation of extremism. Public Prosecutor's supervision should be carried out in a transparent manner. Within the limits provided for by law, citizens and public associations must be informed, with the involvement of the mass media, about the results of the Prosecutor's office's activities to counter terrorism, the state of law and order in the country.

Keywords: law, law and order, Prosecutor's office, subjects of Prosecutor's supervision Prosecutor's supervision.
Зайко Тамара Михайловна

К.ю.н., дочент, Уральский государственный юридический университет, г. Екатеринбург tmzayko@mail.ru

Пантюхина Галина Александровна К.ю.н., дочент, Уральский государственный юридический университет, г. Екатеринбург galina-pantyukhina@yandex.ru

Аннотация: Описаны различные формы проявления экстремизма, которые провоцируют нестабильность в обществе, способствуют ослаблению российской государственности, порождают в отдельных субъектах Российской Федерации сепаратистские настроения и создают для экстремистов благоприятную возможность реализации их целей и задач. Данное обстоятельство приводит к нарушению прав и свобод человека и гражданина, подрывает общественную безопасность и государственную целостность. Создает реальную угрозу основам конституционного строя. Поскольку суть терроризма - насилие с целью устрашения. Терроризм - это крайнее проявление экстремизма. Прокурорский надзор должен осуществляться гласно. В предусмотренных законом пределах граждане, общественные объединения должны информироваться с привлечением средств массовой информации о результатах деятельности прокуратуры по противодействию терроризму, состоянию законности и правопорядка в стране.

Ключевые слова: закон, правопорядок, прокуратура, субъекты прокурорского надзора прокурорский надзор.

Экстремист - это человек, придерживающийся крайних взглядов, сторонник крайних мер. Под экстремизмом понимается приверженность к крайним взглядам и, в особенности, мерам (обычно в политике). Среди таких мер можно отметить провокацию беспорядков, гражданское неповиновение, террористические акции и др. Наиболее радикально настроенные экстремисты часто в принципе отрицают какие-либо компромиссы, переговоры, соглашения.

Росту экстремизма обычно способствуют:

- социально-экономические кризисы;

- резкое падение жизненного уровня основной массы населения;

- политическая нестабильность.

Термин «терроризм» и «террор» стал широко употребляться со времен французской буржуазной революции 1789-1794гг. Чуть позже, в 1798 году словарь Французской академии наук определит его как «систему страха». В Великобритании он получит несколько иное назначение: «правление ужаса» [2].

В «Толковом словаре русского языка» С.И. Ожегова 
предлагается общее определение терроризма: «политика и практика террора», под которым в свою очередь понимается «устрашение своих политических противников», выражающееся в физическом насилии вплоть до уничтожения [3]. Таким образом, характерной особенностью терроризма является опора на силу в достижении своих целей - запугать население и посеять панику.

Под терроризмом в современной политической практике понимается применение негосударственного насилия или угрозы с целью вызвать панику в обществе, ослабить и даже свергнуть правительство, вызвать политические изменения в государстве.

Он направлен на дестабилизацию государственных режимов, возбуждение у населения обеспокоенности из-за своей беззащитности перед лицом насилия, смену государственной власти в стране, на осуществление иных политических, религиозных или этнических требований.

Как известно, для нагнетания страха террористы могут применять захват заложников, поджоги, взрывы жилых домов, зданий общественного назначения: магазинов, вокзалов и т.д.

Террористические действия носят всегда публичный характер, воздействуют или на общество или на власть. Выступая в начале июля 2020 года на заседании Совета Безопасности ООН, генеральный секретарь организации предупредил об опасности роста террористической угрозы на фоне пандемии. В некоторых странах «хрупкие мирные процессы могут быть сорваны в результате кризиса», отметил Антониу Гутерриш. По его словам, члены таких организаций рассматривают глобальную нестабильность как тактическое преимущество.

По данным МВД РФ за период с января по июнь 2020 года в стране зарегистрировано 1183 преступления террористического характера (на 21,7\% больше, чем за аналогичный период 2019 года) и 442 преступления экстремистской направленности (больше на 40,8\%).

Как уже было сказано, суть терроризма - насилие с целью устрашения. Терроризм - это крайнее проявление экстремизма. Терроризм приобрел международный глобальный характер. Сегодня в мире насчитывается более 500 нелегальных террористических группировок.

Эмиссары международного терроризма и боевики из Афганистана, Пакистана, Саудовской Аравии и других стран появились на Кавказе, в республиках Поволжья.

По-прежнему выявляются факты незаконной деятельности радикальных и исламистских, и других организаций запрещённых решением Верховного Суда Российской Федерации.
Так, на отдельных территориях федеральных округов активно осуществляют деятельность сторонники запрещенных международных религиозных объединений: «Таблиги джамаат», «Нурджулар» и др., а также террористической организации «Партия исламского освобождения» («Хизб утТахрир аль-Ислами»).

Ярким примером этому является вынесенный в декабре 2019 года приговор Октябрьским районным судом г. Уфы Республики Башкортостан по фактам участия граждан в организации деятельности экстремисткой организации - приверженцам идей международного религиозного объединения «Нурджулар», деятельность, которой была запрещена решением Верховного Сура РФ от 10.04.2008г. и признана экстремистской [4].

В официальной статистике Судебного департамента Верховного суда в сфере борьбы с экстремизмом за первую половину 2020 года отмечается, что из осужденных в первом полугодии 2020 года 132 человека (за 2019 год - 244) были привлечены к уголовной ответственности по статьям, карающим за разного сорта публичные высказывания (ст. 282, 280, 2801, 2052, 3541, чч. 1 и 2148 УК), а 78 (за 2019 год - 188) - за создание экстремистских или террористических сообществ и продолжение деятельности организаций, которые были запрещены как экстремистские или террористические (ст. 2821, 2822, 2054, 2055 УК).

Как справедливо отмечал бывший заместитель Генерального прокурора Российской Федерации Фридинский С.Н., что государственная система противодействия экстремизму функционирует не столь эффективно, как того требуют реалии сегодняшнего дня. Недостаточно скоординированы действия органов государственной власти. В серьезном совершенствовании нуждается система обмена информацией между заинтересованными ведомствами. В общий процесс почти не включены общественные объединения и другие институты гражданского общества.

Органы государственной власти и местного самоуправления недостаточно оперативно и адекватно реагируют на проявления политического экстремизма. Общество не выработало устойчивого негативного отношения к экстремизму. Не в полной мере осознало степень опасности этого явления для российской государственности, многонационального, поликонфессионального российского народа [5].

Недостаточно внимания уделяется антиэкстремистской пропаганде, разъяснительной работе среди широких кругов населения, профилактике политического экстремизма среди молодежи. А так как, субъектом терроризма может быть любое вменяемое лицо, достигшее четырнадцатилетнего возраста, то это положение приме- 
нительно к рассматриваемому преступлению особенно актуально, поскольку в национальном и религиозной терроризме, как показывает практика, принимает участие довольно много подростков. В условиях массовой истерии они легко могут в силу своего возраста совершать преступные действия, в том числе террористической направленности. Соответственно, именно особенностями личности преступника определяется, в первую очередь, преступность несовершеннолетних, которая сегодня является одной из ключевых проблем российского общества. Количественные показатели подростковой преступности ежегодно возрастают, она приобретает групповой, организованный характер. Включение несовершеннолетних в сферу уголовно-процессуальных отношений выводит вопрос предупреждения преступлений, совершаемых лицами, не достигшими 18 лет, на уровень первоочередных задач государства и общества [6].

В России юридическое определение экстремистских действий содержится в статье 1 Федерального закона № 114-Ф3 от 25 июля 2002 года (в ред. от 08.12.2020) «О противодействии экстремистской деятельности». К экстремистской деятельности относятся:

- насильственное изменение основ конституционного строя и нарушение целостности Российской Федерации;

- публичное оправдание терроризма и иная террористическая деятельность;

- возбуждение социальной, расовой, национальной или религиозной розни;

- пропаганда исключительного превосходства либо неполноценности человека по признаку его социальной, расовой, национальной, религиозной или языковой принадлежности;

- совершение преступлений по мотивам политической, идеологические, расовой, национальной или религиозной ненависти;

- пропаганда и публичное демонстрирование нацистской символики;

- публичные призывы к осуществлению указанных деяний либо массовое распространение экстремистских материалов, а равно их изготовление или хранение в целях массового распространения;

- финансирование указанных действий и т.д. [7].

Согласно вышеуказанному закону противодействие экстремистской деятельности основывается на следующих принципах:

- признания, соблюдения и защиты прав и свод человека и гражданина, а равно законных интересов организаций;

- законности;

- гласности;

- приоритета мер, направленных на предупреждение экстремистской деятельности;
- сотрудничества государства с общественными и религиозными объединениями и гражданами в противодействии экстремистской деятельности;

- неотвратимости наказания за осуществление экстремистской деятельности [7].

Субъектами противодействия экстремистской деятельности являются органы государственной власти и местного самоуправления. Они участвуют в противодействии экстремистской деятельности в пределах своей компетенции.

Главным образом вопросы противодействия экстремизму в Российской Федерации относятся к компетенции департамента по противодействию терроризму МВД России.

Координацию деятельности федеральных органов исполнительной власти по противодействию экстремистской деятельности осуществляет Генеральный прокурор РФ. Правовой основой для определения объектов прокурорского надзора за исполнением законодательства в системе противодействия экстремизму являются п. 1 ст. 21, п. 2 ст. 26 Федерального закона «О прокуратуре Российской Федерации» [8].

По этой причине в соответствии с указанным законом прокурорский надзор за исполнением законов о противодействии экстремистской деятельности в современных условиях является одним из наиболее значимых, актуальных и приоритетных направлений надзорной деятельности органов прокуратуры по укреплению законности и правопорядка [9].

Специфика прокурорско - надзорной деятельности в указанной области предупредительной деятельности определяется наличием значительного количества органов государственной власти, осуществляющих противодействие экстремизму в РФ. В этих условиях особое значение приобретает осуществление надзора за исполнением законодательства о противодействии экстремизму в органах: МВД России, Минюста России, Федеральной службы по надзору в сфере связи, информационных технологий и массовых коммуникаций (Роскомнадзор), Федеральной миграционной службы (ФМС России), Федеральной службы по надзору в сфере образования и науки (Рособрнадзор), уполномоченного по правам ребёнка, органы опеки и попечительства, комиссий по делам несовершеннолетних и защите их прав и др.

Поскольку задачи предупреждения экстремистской деятельности решается совместными усилиями не только правоохранительных органов, но и общественными и религиозными организациями, поэтому у прокурорских работников возникает необходимость разработки комплексных планов проведения профилактических меро- 
приятий в данной сфере правового регулирования.

В целях повышения эффективности прокурорского надзора за исполнением вышеуказанного Закона, Генеральный прокурор РФ обращает особое внимание на профилактику данных правонарушений, требуя от территориальных, военных и других специализированных прокуроров обеспечить эффективную систему надзора за исполнением законодательства по противодействию терроризму.

Особое внимание Руководитель высшего государственного надзорного органа обращает на то, чтобы подчиненные ему прокуроры надзирали за исполнением закона, направленного на исключение фактов, пропаганды идей терроризма распространения материалов или информации, призывающих к осуществлению террористической деятельности либо обосновывающих необходимость ее осуществления.

Для достижения поставленной задачи, по мнению авторов, предлагается:

- проанализировать и обобщить практику прокурорского надзора в сфере противодействия экстремистской деятельности;

- выработать предложения по повышению эффективности деятельности прокуратуры в рассматриваемой сфере правового регулирования;

- ежегодно проводить анализ состояния законности, в целях выявления типичных правонарушений в указанной сфере;

- прогнозировать перспективы и определять приоритетные задачи развития законодательства о противодействии экстремистской деятельности на современном этапе;

- выявлять особенности применения средств прокурорского надзора в прокуратуры в рассматриваемой сфере правового регулирования.

Деятельность прокуратуры, как надзорного органа распространяется на различные сферы государственной и публичной деятельности.

Так, при выявлении информационных материалов, содержащих публичные призывы к осуществлению террористической деятельности, Генеральный прокурор РФ может требовать безотлагательного решения вопроса о направлении материалов в следственные органы с целью уголовного преследования, а также иных мер прокурорского реагирования.

При осуществлении надзора за оперативно-розыскной и уголовно-процессуальной деятельностью по выявлению и пресечению преступных действий террористического характера Генеральный прокурор может требовать от последних принятия всех необходимых мер по выяснению причастности виновных лиц к организации деятельности террористических организаций, общественных и религиозных объединений, незаконных вооружённых формирований в зависимости от степени участия последних в противоправных действиях.

В ходе расследования преступлений террористического характера органы предварительного следствия и органы его сопровождающие должны принимать исчерпывающие меры по установлению лиц, причастных к совершению преступлений, выявлению причин и условий, способствовавших их совершению, использовать все возможности для установления источников финансирования преступной деятельности и пресечения их использования для совершения других преступлений.

Большое значение Генеральный прокурор РФ придает поддержанию государственного обвинения в судах. В связи с изменением уголовно-процессуального законодательства (далеко не в пользу потерпевших), в судах, рассматривающих уголовные дела о преступлениях террористического характера, должны участвовать наиболее опытные, квалифицированные государственные обвинители. В каждом случае постановления незаконного, необоснованного или несправедливого судебного решения они должны обеспечить апелляционное или кассационное его опротестование.

Прокурорские работники о наиболее серьезных нарушениях законности, способствующих террористической деятельности, и принятых мерах прокурорского реагирования незамедлительно информируют Генерального прокурора Российской Федерации.

Согласно Конституции Российской Федерации прокурорский надзор должен осуществляться гласно [10].

В предусмотренных законом пределах граждане, общественные объединения должны информироваться с привлечением средств массовой информации о результатах деятельности прокуратуры по противодействию терроризму, состоянию законности и правопорядка в стране. Поэтому требуется усиление информационнопропагандистская работы, направленной на формирование у граждан позитивного отношения к принимаемым мерам по противодействию террористическим проявлениям.

Таким образом, предприняв попытки проанализировать вопрос противодействия экстремизму (терроризму) силами прокурорского надзора приходим к выводам:

- повышение качества и результативности прокурорского надзора за исполнением законов о противодействии экстремистской деятельности должно быть неразрывно связано с необходимостью взаимодействия всех сил органов правопорядка; 
- необходимо постоянное обобщение практики прокурорского надзора

- по результатам обобщения вносить рекомендации по совершенствованию законодательства о прокурорском надзоре.
Рассмотренные аспекты данной проблемы, безусловно, не исчерпывают всего круга вопросов этой темы. Тем не менее, их обсуждение, надеемся, будет способствовать активизации борьбы с этими опасными явлениями в нашем обществе.

\section{ЛИТЕРАТУРА}

1. Указ Президента Российской Федерации от 29.05 .2020 г. № 344 «06 утверждении Стратегии противодействия экстремизму в Российской Федерации до 2025 года»

2. Словарь Французской академии наук 1798г.Libex.ru-detail/book-465699.ntml/

3. Ожегов С.И. Словарь русского языка / Под ред. Н.Ю. Шведовой. М.1984. С.253

4. Архив Октябрьского райсуда г. Уфы 2017г. / Уголовное дело №1-6/2017

5. Фридинский С.Н. Некоторые проблемы противодействия экстремизму в Российской Федерации//Право и безопасность. 2006. №1-2. С.18-19.

6. Зайко Т.М. Актуальные вопросы предупреждения правонарушений несовершеннолетних// Сб. научных трудов по материалам международной научнопрактическая конференции. Ч. 3: 30.12.2016: «Вопросы образования и науки»: Тамбов, 2016/ https:/ucom.ru/co. С.40

7. Федеральный закон № 114-Ф3 от 25 июля 2002 года (в ред. от 08.12.2020) «0 противодействии экстремистской деятельности»

8. Федеральный закон №168 от 17 ноября 1995 года (с имениями на 9 ноября 2020 года) «0 прокуратуре Российской Федерации»

9. Пантюхина Г.А. К вопросам истории прокуратуры Свердловской области//Историческая и социально-образовательная мысль. 2019. Том. 11. № 3. С. 39-53

10. Конституция Российской Федерации (с изменениями на 14 марта 2020 года). Принята всенародным голосованием 12 декабря 1993 года с изменениями, одобрениями в ходе общероссийского голосования 1 июля 2020 года

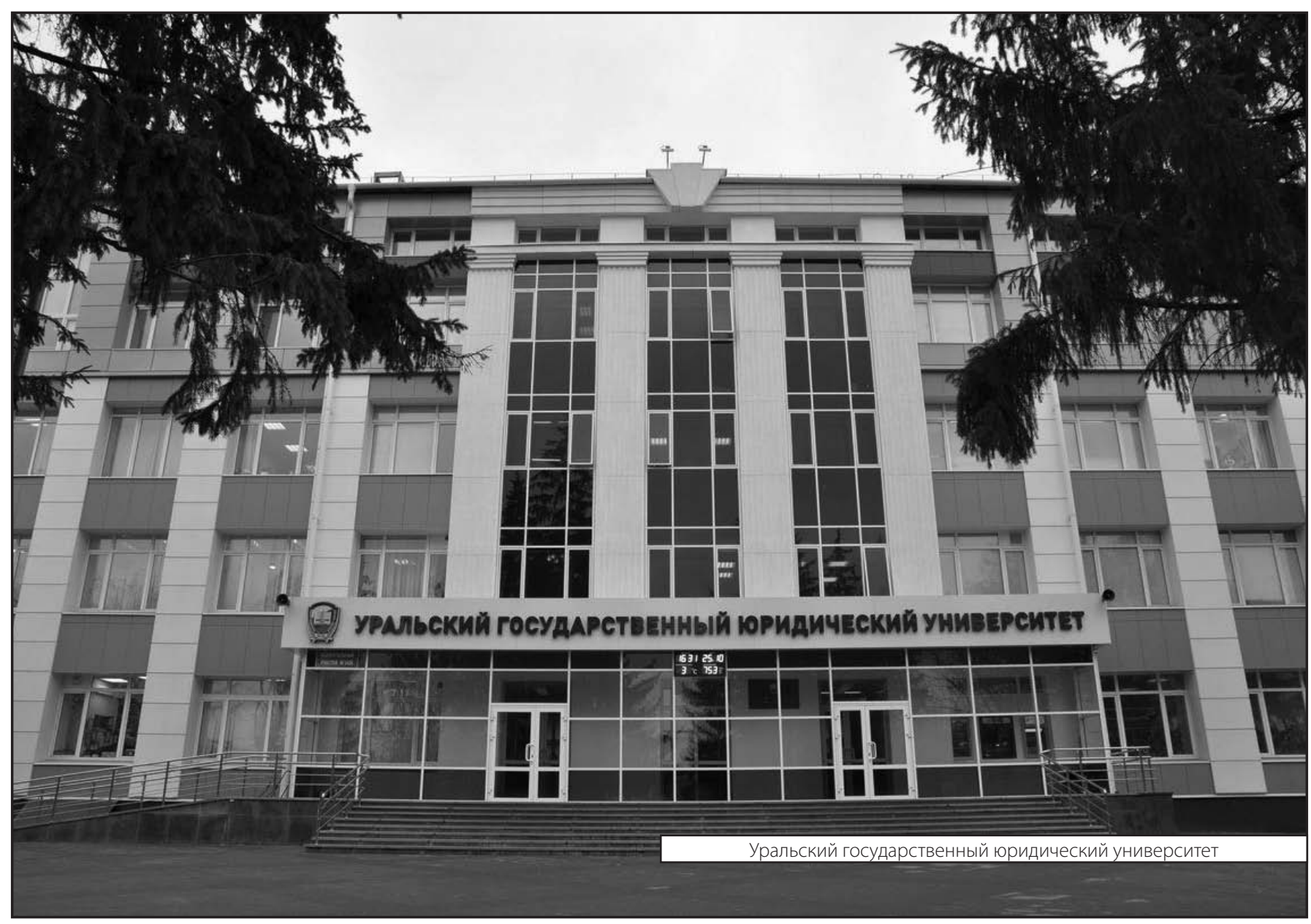

